\title{
Total costs and benefits of biomass in selected regions of the European Union
}

H.-M. Groscurth ${ }^{a, *}$, A. de Almeida ${ }^{\text {b }}$, A. Bauen ${ }^{\text {c }}$, F.B. Costa ${ }^{\text {b }}$, S.-O. Ericson ${ }^{\text {d, }}$ J. Giegrich ${ }^{\mathrm{e}}$, N. von Grabczewski ${ }^{\text {a }}$, D.O. Hall ${ }^{\mathrm{c}}$, O. Hohmeyer ${ }^{\mathrm{a}}$, K. Jörgensen ${ }^{\mathrm{f}}$, C. Kern ${ }^{\mathrm{g}}$, I. Kühn ${ }^{\mathrm{a}}$, R. Löfstedt ${ }^{\mathrm{f}}$, J. da Silva Mariano ${ }^{\mathrm{b}}$, P.M.G. Mariano ${ }^{\mathrm{b}}$,

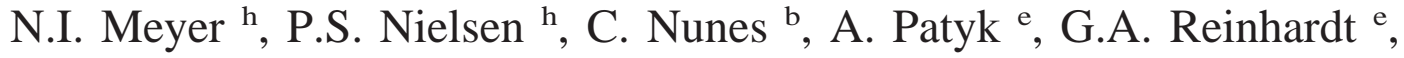
F. Rosillo-Calle ${ }^{c}$, I. Scrase ${ }^{c}$, B. Widmann ${ }^{g}$

${ }^{a}$ Zentrum für Europäische Wirtschaftsforschung GmbH (ZEW), P.O. Box 1034 43, D-68034 Mannheim, Germany

${ }^{\mathrm{b}}$ King's College, University of London, Division of Life Sciences, London, UK

${ }^{c}$ Vattenfall Utveckling AB, Bioenergy Programme, Stockholm, Sweden

${ }^{d}$ Technical University of Denmark, Department of Buildings and Energy, Lyngby, Denmark

e University of Coimbra, Instituto de Sistemas e Robotica, Portugal

${ }^{\mathrm{f}}$ Bayerische Landesanstalt für Landtechnik, TU München-Weihenstephan, Germany

g University of Surrey, Centre for Environmental Strategy, Guildford, UK

${ }^{\mathrm{h}}$ Institut für Energie- und Umweltforschung GmbH (ifeu), Heidelberg, Germany

Received 1 September 1999

\begin{abstract}
The paper describes results of the BioCosts project in which a comprehensive analysis of the economic and environmental performance of the energy use of biomass was carried out for selected existing facilities throughout the European Union. It is demonstrated that the appropriately organized use of biofuels has significant environmental advantages compared to the use of fossil fuels. Mitigation of global warming is the largest single incentive to use biofuels. However, only a few technologies are economically competitive under prevailing conditions, while others lead to up to $100 \%$ higher energy production costs than fossil fuels. Employment effects of using biofuels are small but positive. (C) 2000 Elsevier Science Ltd. All rights reserved.
\end{abstract}

\footnotetext{
* Corresponding author. Fax: +49-40-6396-3334.

E-mail address: groscurth.ekz@hew.de (H.-M. Groscurth).
} 


\section{Objectives and methodology}

Biomass is the renewable energy source which is often believed to have the highest potential to contribute to a future sustainable energy supply for the European Union [1]. In Finland, Sweden, and Austria, it currently already covers shares of 23,18 , and $12 \%$ of the primary energy demand, respectively. Biomass is different from other renewable energy sources due to the variety of solid, liquid and gaseous fuels which may be derived from it and to the very different conversion technologies applicable for their utilization. A major advantage lies in the fact that biofuels are $\mathrm{CO}_{2}$-neutral. Moreover, they can be stored and may thus compensate for the intermittent character of other renewable energy sources.

The objective of the project 'Total Costs and Benefits of Biomass in Selected Regions of the European Union (BioCosts)' has been to provide a comprehensive analysis of the economic and environmental performance of the energy use of biomass [2]. For this purpose, a number of representative biomass-to-electricity and biomass-to-transport-service fuel cycles located at different sites within the European Union were evaluated. Due to limited space, only the first category of case studies is covered in this paper. These case studies are listed in Table 1. In general, existing installations with sufficient operating experience were analyzed and only in a few cases were planned installations included. Each biomass technology is compared to a fossil fuel fired reference technology.

For the economic and environmental appraisal, the fuel cycles were divided into fuel production, conversion and clean-up stages. Assessing the economic performance involved production costs of energy as well as employment effects. Production costs are composed of investment, labor, fuel and (other) operation and maintenance costs. Country specific effects such as taxes and subsidies were disregarded as far as possible. Direct employment in the biomass fuel cycles was obtained from the operators. Indirect employment from the manufacture of equipment and employment for the production of fossil fuels were calculated with ZEW's enhanced input-output model EMI $2.0[3,4]{ }^{1}$

For each stage of the different biomass fuel cycles and their reference cases, a detailed inventory of direct emissions and burdens was compiled. Indirect emissions were obtained with the I/O model EMI 2.0.

A prominent task of the BioCosts project was to determine the 'external costs' of the energy use of biomass. In neo-classical economic theory, external costs are defined as those costs of a product or service which are not paid for by the user, but by otherwise uninvolved third parties. A number of extensive research projects have been carried out on this topic during recent years [5-10]. Nevertheless, severe uncertainties remain in any estimate of external costs arising from environmental damage. Some uncertainties arise from a lack of knowledge, but a substantial share is related to fundamental methodological and ethical problems which have not yet been (and may never be) resolved. It is beyond the scope of this paper to cover this discussion in more detail [e.g. Ref. 11]. However, it is important to record that many researchers come to the conclusion

\footnotetext{
${ }^{1}$ Input-output tables describe the interaction between different economic sectors via deliveries and purchases in monetary terms. In addition, there are coefficients which represent the specific labor input within the different sectors and which allow for calculating the accumulated labor input along the supply chain. The I/O model EMI 2.0 of ZEW also features emission coefficients which render it possible to calculate indirect emissions along the supply chain.
} 
Table 1

Case studies of the BioCosts project

\begin{tabular}{|c|c|c|c|}
\hline \multirow[t]{2}{*}{ Case study } & \multirow[t]{2}{*}{ Installation/location } & \multicolumn{2}{|c|}{ Abbreviation } \\
\hline & & $\begin{array}{l}\text { Biomass } \\
\text { case }\end{array}$ & $\begin{array}{l}\text { Reference } \\
\text { case }\end{array}$ \\
\hline $\begin{array}{l}\text { Utilization of forest residues and saw-mill waste in a circulating } \\
\text { fluidizedbed combustion, combined with heat and power (CHP) } \\
\text { plant vs the use of Polish coal in the same plant }\end{array}$ & $\begin{array}{l}\text { CHP plant, } \\
\text { Nässjö, Sweden }\end{array}$ & sl-o & sl-r \\
\hline $\begin{array}{l}\text { Utilization of woody biomass for industrial combined heat and } \\
\text { power production vs the use of fuel oil in a diesel engine } \\
\text { generating heat and power }\end{array}$ & $\begin{array}{l}\text { Wood-board factory, } \\
\text { Mangualde, Portugal }\end{array}$ & & \\
\hline Case 1: forestry residues and saw-mill waste & & pl-o & pl-r \\
\hline Case 2: Short-rotation coppice & & $\mathrm{p} 2-\mathrm{o}^{\mathrm{a}}$ & $\mathrm{p} 2-\mathrm{r}$ \\
\hline $\begin{array}{l}\text { Production of biogas from animal slurry and industrial organic } \\
\text { waste for a CHP engine vs the use of Danish natural gas in the } \\
\text { same engine }\end{array}$ & $\begin{array}{l}\text { Municipal CHP plant, } \\
\text { Hashöj, Denmark }\end{array}$ & $\mathrm{dk}-\mathrm{o}$ & dk-r \\
\hline \multicolumn{4}{|c|}{ Gasification of woody biomass } \\
\hline $\begin{array}{l}\text { High pressure gasification of forestry residues vs the use of coal } \\
\text { in the Nässjö plant (sl-r) }\end{array}$ & $\begin{array}{l}\text { Municipal CHP plant, } \\
\text { Värnamo, Sweden }\end{array}$ & s2-o & $\mathrm{s} 2-\mathrm{r} \approx \mathrm{sl}-\mathrm{r}$ \\
\hline $\begin{array}{l}\text { Atmospheric pressure gasification of short-rotation coppice and } \\
\text { forestry residues vs the use of coal at a coal combustion power } \\
\text { plant }\end{array}$ & $\begin{array}{l}\text { Powerplant, } \\
\text { Eggborough, UK }\end{array}$ & $\mathrm{uk- \textrm {o } ^ { \mathrm { a } }}$ & uk-r \\
\hline $\begin{array}{l}\text { Production of cold-pressed rape-seed oil and its use in an adapted } \\
\text { CHP diesel engine plant vs the use of diesel fuel in a similar } \\
\text { engine }\end{array}$ & $\begin{array}{l}\text { Municipal CHP plant, } \\
\text { Weissenburg, Germany }\end{array}$ & dl-o & dl-r \\
\hline
\end{tabular}

a Planned installations/under construction.

that the traditional objective of neo-classical economics, that is to reach a Pareto optimal statein which no one can be made better off without someone else becoming worse off-may be too ambitious with respect to environmental problems.

Nevertheless, decision makers need advice when tackling the severe environmental problems which industrial societies face today. Therefore, we agree with Miser and Quade [12], who state that "systems analysis is the multidisciplinary problem-solving activity that has evolved to deal with the complex problems that arise in public and private enterprises and organizations." While expectations for obtaining precise scientific facts in relation to environmental problems are often limited, the goal of systems analysis is clearly to suggest actions or decisions with a limited budget of time and money even if the knowledge of the system is incomplete. Consequently, the BioCosts project has tried to provide a number of indicators for the economic and environmental performance of biomass fuel cycles which may help decision makers to reach conclusions. By stating methodological problems openly, we want to put decision makers in a position where they can make their personal choice between methodologies and corresponding assumptions and where they will be able to determine the consequence of these choices. 
We would like to stress that the external costs related to damage to human health, which are given in this article, are based on values of the present generation (insofar as they can be measured at all) and may, thus, be subject to change in the future. We will present only those effects which have a significant influence on the total figures and we will state damage costs only for impacts for which the physical damage can be measured with sufficient precision.

Consequently, in the BioCosts project, external costs could only be estimated for the impacts of direct emissions of $\mathrm{NO}_{\mathrm{x}}, \mathrm{SO}_{2}$ and dust particles and the related secondary emissions on human health. The calculations were carried out with the computer model EcoSense (Version 2.0) developed within the ExternE project [5,6]. The model implements an impact-pathway approach, comprising the air dispersion of pollutants, formation of secondary pollutants (nitrates and sulfates), changes of the atmospheric concentration of pollutants all over Europe, quantification of physical impacts via exposure-response functions, and monetization of these impacts.

Externality assessment and, thus, cost-benefit analysis were not considered an appropriate tool for the issue of global warming. Neither the damage avoided nor the abatement costs of climate change can be determined with sufficient accuracy [11]. Therefore, we applied the concept of strong sustainability as suggested, for instance, by Daly [13]. Damage to the environment is then no longer offset by economic benefits but has to be limited independently. The definition of such limits should be the subject of a broad public debate and, ideally, decisions should be based on a broad consensus. For the implementation of such limits, economic tools like taxes or tradable emission permits may well be applied instead of the still dominating command-and-control measures. As an indicator of the costs of such a strategy to mitigate global warming, one may resort to the costs of avoiding to emit an additional unit of infra-red active gases (i.e. carbon dioxide, methane etc.).

When defining the different stages of the fuel cycle, it is essential to carefully select system boundaries and allocation mechanisms. System boundaries define which effects are regarded as part of the fuel cycle and which are left out of consideration. Allocation mechanisms are necessary to attribute the effects analyzed to the different commodities produced.

The general rule for defining system boundaries in the BioCosts project was to compare the biomass-to-energy application with its fossil fuel reference case and to attribute any difference, be it positive or negative, beneficial or potentially harmful, to the use of biomass. For agriculture, the farming of energy crops was compared to what would otherwise take place on that piece of land. This may be conventional farming of food crops or participation in the EU's set-aside land scheme. For combustion, the efficiencies, costs, and emissions of the use of biofuels were compared to those of fossil fuels. In addition to these direct effects, indirect effects of manufacturing the equipment for conversion and for fuel preparation were taken into account. This was done via input-output analysis. Finally, other indirect effects, which were not captured by the I/O model, were considered if they contributed significantly to the overall impacts. This was the case for the application of fertilizers during farming of energy crops. The production of the fertilizers needs relatively large amounts of (fossil) energy and it causes emissions that contribute substantially to the respective emission inventories [14].

For all but one case study, it was necessary to allocate impacts and costs between different commodities. Mostly, these commodities were electricity and heat, but in some cases marketable by-products such as press cake, which can be sold as fodder, had to be taken into account. However, there is no unique solution to this problem which has no disadvantages. For electricity and 
heat, the most favorable, largely unbiased solution is the systems approach. It considers two systems, which supply the same energy services, and calculates the respective costs and environmental impacts which may then be compared to decide which solution is to be preferred. However, this approach was not applicable here since we were obliged to produce results with respect to one unit of heat or electricity. In the end, we decided to use energy allocation, which means that emissions and internal costs are attributed to electricity and heat flows according to their energy content. Thus, one $\mathrm{kWh}$ of electricity is regarded as equivalent to one $\mathrm{kWh}$ of heat. ${ }^{2}$ This will ensure comparability of the results of different case studies, but will have to be kept in mind when comparing our results with actual market prices of energy. For non-energy by-products such as press cake from rape production, which occur during the production of biofuels, we have used allocation by mass since allocation by energy would obviously be meaningless. Further impacts of the by-products, such as avoided emissions during the production of fodder which is now substituted by press cake, have not been included in the results.

\section{Case studies: biofuels for the production of heat and power}

\subsection{Economic performance: internal costs and employment effects}

The internal costs of the different facilities analyzed in the BioCosts project are summarized in Fig. 1. Abbreviations are explained in Table 1. Altogether, the results show a broad range of energy production costs. Only two biofuel cases have lower energy production costs than their reference cases at current (1998) fossil fuel prices. These are the industrial combined heat and

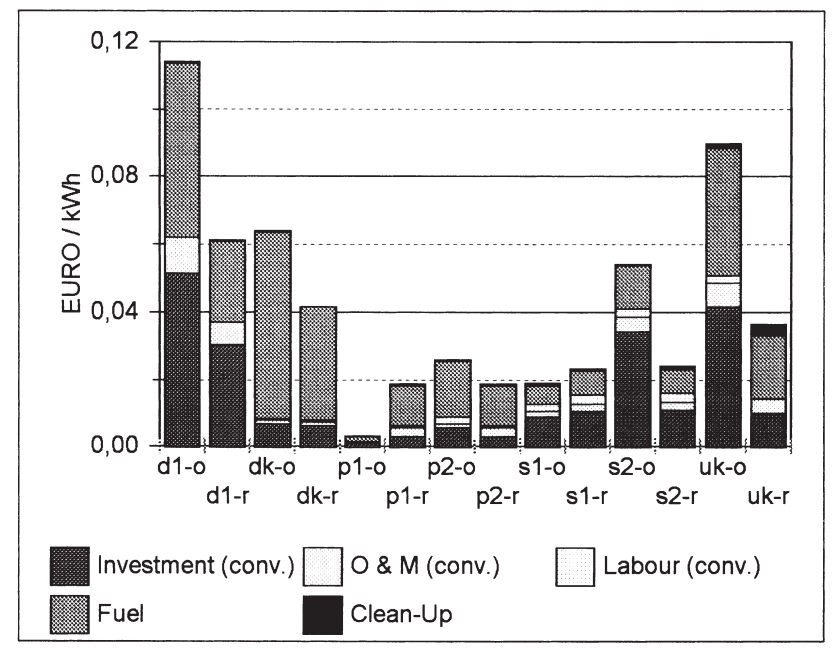

Fig. 1. Energy production cost of BioCosts case studies. Costs of the conversion (conv.) stage are split into investment, operation and maintenance $(\mathrm{O} \& \mathrm{M})$ and labor. Abbreviations are defined in Table 1.

2 This is done in spite of the different exergy content and, hence, energetic quality. Using exergy would allocate the more emissions to electricity the better the electric efficiency is. We did not consider this justified. 
power (CHP) facility at Mangualde, Portugal, (Case p1-o: $3.0 \mathrm{mEURO} / \mathrm{kWh}$ ) and the CHP plant at Nässjö, Sweden (Case s1-o: $19 \mathrm{mEURO/kWh).} \mathrm{Both} \mathrm{use} \mathrm{forestry} \mathrm{residues} \mathrm{and} \mathrm{saw-mill} \mathrm{waste}$ as a fuel. ${ }^{3}$ Other biofuel facilities are up to $100 \%$ more expensive than their reference case.

The gasification schemes (s2-o, uk-o) are dominated by high investment costs of the conversion equipment, which includes the gasification equipment as for these integrated facilities. It is not always obvious to determine which part of the equipment belongs to which fuel-cycle stage. There should be a significant potential for cost reductions for these demonstration facilities.

The biogas fuel cycle in Denmark (dk-o) turned out to be relatively expensive, but not much more expensive than its reference case. The high cost level is partly due to the decentralized character of the installation while the small difference compared to the reference system is due to natural gas being the most expensive fossil fuel. The additional cost for biogas is due to the early stage of biogas technology development. The second Portuguese case (p2-o) involving shortrotation coppice has a good potential of becoming economic if the costs of biofuel production can be reduced or if fossil fuels become more expensive (e.g. for environmental reasons or due to increased demand). The rape-seed oil case (d1-o) does not seem favorable, even if one considers much longer hours of operation, since the potential for cost reduction appears limited.

It should be emphasized that the cost figures stated here are not those relevant for business calculations as they would include taxes and apply a different method of allocating costs between heat and electricity. Thus, the figures given reflect a general economic perspective rather than a (private) business perspective.

In Fig. 2, the employment effects of the case studies are summarized. The figure shows two indicators for specific employment, one with respect to energy production costs and the other in relation to the amount of energy supplied. Employment figures have to be considered with care since the different fuel cycles are at very different stages of development and their costs and

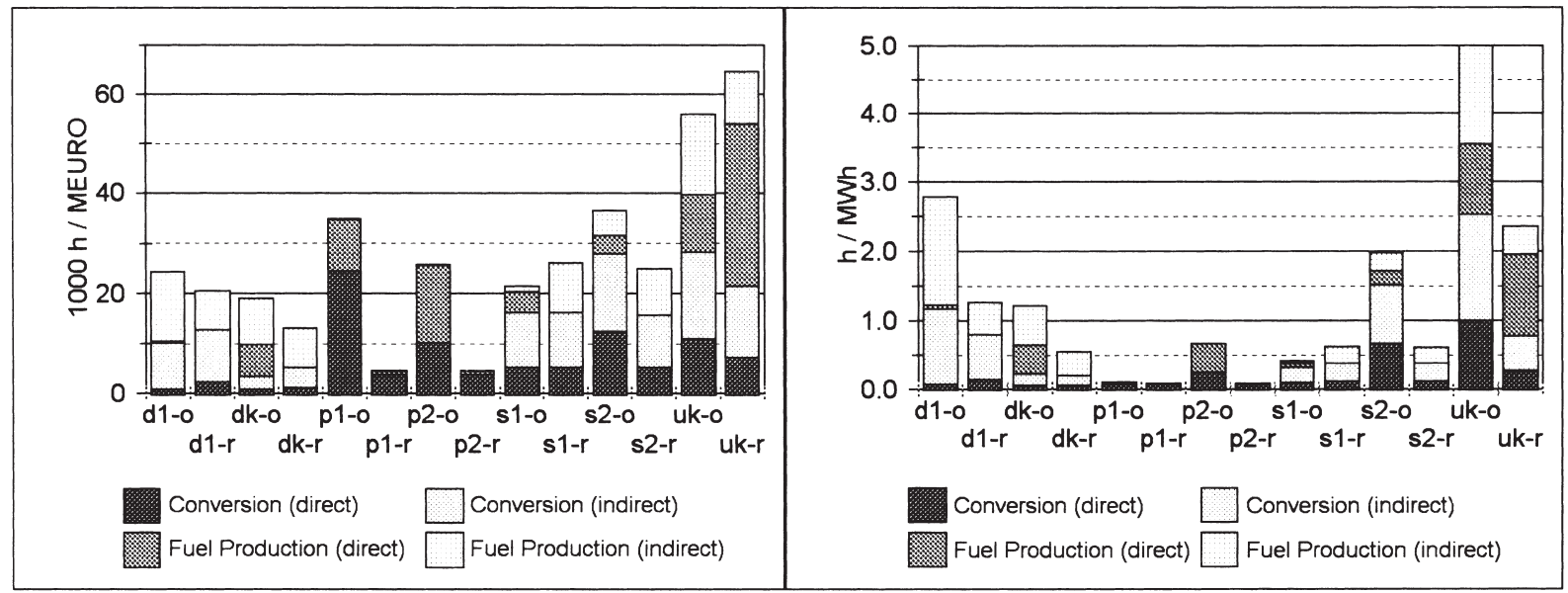

Fig. 2. Specific employment effects of BioCosts case studies with respect to production costs (1000 h/EURO) and energy output (h/MWh). Abbreviations are defined in Table 1.

${ }^{3}$ All cost figures are stated in EURO ( $\boldsymbol{\ell}$ ), MilliEURO (mEURO) or MegaEURO (MEURO) where 1 EURO is equivalent to 1 ECU, the former European Currency Unit. $1 \in=1.06$ US\$ in July 1999. The base year for all cost figures is 1990 . 
efficiencies vary widely. In addition, the two indicators sometimes lead to quite different conclusions which needs careful interpretation. In general, it may be observed that the better developed a technology is, the smaller are the positive employment effects.

For rape-seed farming (d1-o), 65\% of the employment has to be allocated to the press cake residue according to its mass. Consequently, in monetary terms, the labor intensity of the rapeseed oil fuel cycle is only slightly higher than the intensity of its reference case (cf. Fig. 2). This is caused by the fact that rape-seed oil production is much more costly than diesel production since the former is more labor intensive, and by to the fact that the extraction of the mineral oil does not take place in Germany. On the other hand, in physical terms, the labor intensity of the rape-seed oil fuel cycle exceeds that of the diesel fuel cycle by more than a factor of two, since the energy efficiencies are comparable. Thus, if the same energy services are to be supplied, the biofuel cycle needs more labor. Finally, it has to be noted that the large share of indirect effects on the conversion stage is caused by the unconventional operation schedule of the CHP plant. If one assumes 5000 instead of the actual 1260 full-load hours, this share is reduced to about the same magnitude as in the Danish case (dk) which uses comparable equipment.

The Danish biogas case (dk-o) is also similar to the rape-seed oil case (d1-o) in that it exhibits higher employment than its reference case due to fuel production. However, the specific labor input for fuel production is smaller than in the German case, because biogas production is less labor intensive than agricultural activities. The fuel substituted is Danish natural gas, which is fully produced within the country itself. It may well be the case that the labor necessary to produce the natural gas is underestimated here, because no direct figures were available. The I/O model results on fossil fuel production in Denmark include substantial uncertainty, because there are no separate economic sectors for the oil, gas and coal industries in the Danish input-output tables used.

For the Portuguese case studies (p1, p2), no indirect effects could be calculated due to the missing input-output table. Direct effects show significantly higher specific employment with respect to production costs for the biofuel than for fossil fuel. The reason may be that, especially in case (p1), the production costs of the reference case (p1-r) are very low. If based on the energy produced, the employment benefit vanishes almost completely.

For the use of forestry residues and saw-mill waste in Sweden (s1-o), we find 20\% lower specific employment than for the reference case (s1-r) using Polish coal. The indirect employment effect for the fossil fuel cycle was again determined by feeding the fuel costs into the energy sector of the Swedish economy in the EMI model. The result can be explained by the low labor input for collection and chipping and by the higher energy output of the biofuel version of the plant.

The gasification scheme in Sweden (s2-o), which is compared to the same reference case as the residue combustion fuel cycle $(\mathrm{s} 2-\mathrm{r} \approx \mathrm{s} 1-\mathrm{r})$, requires more labor input than the fossil fuel case since this scheme involves a significant effort for fuel preparation. In addition, the technology has currently high investment costs which results in high employment figures in EMI runs. They are probably overestimated. Since the costs are likely to decrease as the technology matures, employment figures will fall accordingly.

The same is true for the gasification scheme in the UK (uk-o). Here, however, the reference case has higher specific employment figures than the biofuel case with respect to costs since it assumes the use of UK coal, which is produced nationally and at a relatively low productivity 
compared to other economic sectors. Moreover, the specific employment figures are higher than those of other case studies since only electricity is produced in this case.

It may be concluded that the use of biofuels has small benefits over using fossil fuels with respect to employment, particularly if the fuel preparation process is complex, if it is carried out efficiently, and if they substitute imported fuels. The labor input for biofuels will have to decrease during continuing efforts to make the respective fuel cycles more competitive.

For Germany, it was estimated that supplying 5\% of its energy demand from biomass would result in some 60-120 thousand jobs [15]. However, these jobs would not be created in addition to existing jobs, but would mostly substitute other jobs. First, the jobs for operating the reference technology would be void. Second, if the biofuel technology is more expensive than the fossil fuel technology, the extra money spent would not be available for other purposes such as, for instance, consumption. Jobs in the respective sector of the economy, e.g. in the production of consumer goods, would be lost. All in all, there is probably a small positive net effect in using renewable energy sources. Thus it appears that they will not contribute significantly to solving the unemployment problems which many European countries face today but may maintain jobs especially in the rural areas [cf. also Ref. 1].

\subsection{Environmental impacts: emissions, external costs, and global warming}

Fig. 3 shows the emissions of conventional air pollutants and $\mathrm{CO}_{2}$-equivalent emissions for the case studies with respect to the total energy output (electricity plus heat) of the facilities. For the UK case, emission values are in general higher than in the other cases since it is the only facility solely producing electricity. Therefore, it has a lower overall energy efficiency than the other case studies.

The emission inventories are dominated by the energy conversion stage of the fuel cycle while the clean-up stage has virtually no discernable impact. The contribution of fuel productionthough small in general-is the larger the more complicated the process is.

The highest VOC emissions were found for burning wood in the industrial CHP installation in Portugal (p1-o and p2-o) with results between 0.4 and $0.8 \mathrm{~g} / \mathrm{kWh}$. Fuel-cycles applying diesel engines (d1-o, d1-r, p1-r, p2-r) cause VOC emissions between 0.1 and $0.2 \mathrm{~g} / \mathrm{kWh}$ which are mainly due to the conversion technology. VOC emissions of the biogas fuel cycle (dk-o) as well as the UK gasification scheme (uk-o) and its reference case (uk-r) are also in the latter range. However, they are determined by fuel production rather than by the conversion process. The use of natural gas in the Danish CHP unit (dk-r) and all Swedish case studies (s1-o, s1-r, s2-o, s2r) have very low VOC emissions, well below $0.05 \mathrm{~g} / \mathrm{kWh}$.

The diesel engines in Germany (d1-o, d1-r) and in Portugal (p1-r=p2-r) have by far the highest $\mathrm{NO}_{\mathrm{x}}$ emissions of all case studies. This is not related to the use of biofuels, but determined by the technology. Hence, the problem may be reduced by adding appropriate flue gas cleaning equipment. The Swedish case studies show that it is possible to keep $\mathrm{NO}_{\mathrm{x}}$ emissions of biomass fuel cycles at very low levels.

There is a substantial benefit in low $\mathrm{SO}_{2}$ emissions for all biofuel case studies as there is almost no sulfur in biofuels and contributions from fossil fuels during biofuel production are small. The only exception is biogas competing with natural gas (dk-r), since the latter also hardly contains any sulfur. 


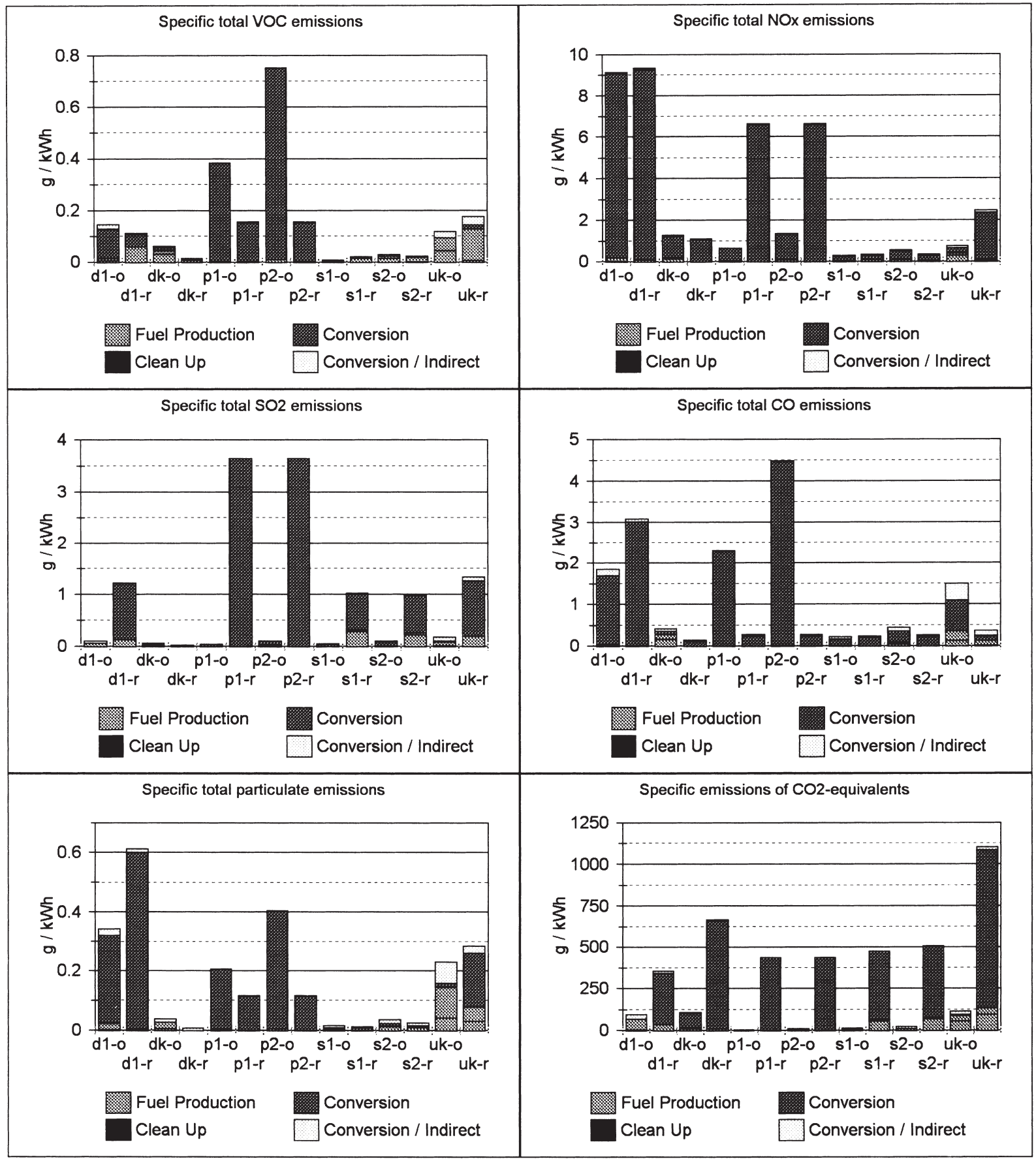

Fig. 3. Summary of the total specific emissions of air pollutants of BioCosts case studies. Abbreviations are defined in Table 1. $\mathrm{CO}_{2}$-equivalents refer to $\mathrm{CO}_{2}$ emissions from fossil sources plus weighted emissions of $\mathrm{CH}_{4}$ and $\mathrm{N}_{2} \mathrm{O}$. 
A number of biomass cases exhibit rather high $\mathrm{CO}$ emissions (d1-o, d1-r, p1-o, p2-o, uk-o), which is again more related to the conversion technology than to the fuel. The high emission levels can be traced to less demanding emission standards or the little attention paid to this problem. The gasification schemes, for example, have probably not been optimized to that end since they are demonstration units. UK reference case emissions, on the other hand, seem particularly low. As the other case studies show, there is no technical reason which prevents lower $\mathrm{CO}$ emissions if this is made an objective. The same is true for particulate emissions, which are low in the Scandinavian cases, but rather high for all other installations.

Finally, Fig. 3 illustrates that emissions of $\mathrm{CO}_{2}$-equivalents are typically reduced by a factor of 10 or more by using biofuels instead of fossil fuels. Only rape-seed oil (d1) and biogas (dk) deviate somewhat. In the latter case, the reduction is only by a factor of 6 due to methane emissions of the internal-combustion engine. These emissions may be avoided if a turbine was used instead. This would also help to reduce $\mathrm{NO}_{\mathrm{x}}$ emissions. For rape-seed oil, emissions are only decreased by a factor of 4 since the production of the fertilizers applied requires substantial amounts of fossil fuels.

Fig. 4 compares the internal and external cost figures calculated. External costs refer to human health impacts by air pollutants calculated with the regional dispersion model of EcoSense. In all cases, the results are dominated by chronic mortality caused by secondary pollutants, namely nitrates and sulfates, based on an exposure-response function derived from Pope et al. [16]. These impacts are monetized via a 'years-of-life-lost (YOLL)' approach, where a monetary value is attached to the number of years a person died earlier than statistically expected. In earlier versions, EcoSense used a value of a statistical life of 3.1 million EURO which is still the basis of calculating the value of a life-year lost. The discount rate used is $0 \%$ [5]. Other relevant impacts comprise chronic bronchitis, asthma, acute mortality and restricted activity days. All other impacts on human health, contributions of local dispersion modeling and impacts on crops, forestry, and buildings covered by the EcoSense model have been found to be insignificant.

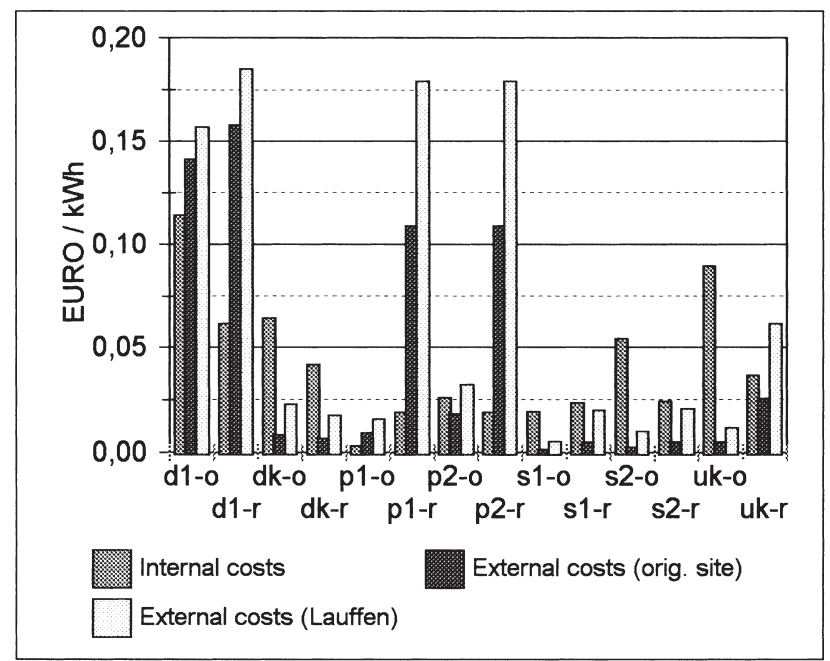

Fig. 4. Internal and external costs of BioCosts case studies at the original site and at Lauffen, Germany. 
External costs are stated for the original site of each technology and also for the hypothetical case in which it is assumed that the technologies were installed at Lauffen near Stuttgart in the southwest of Germany. The latter analysis was included to enhance the comparability of the technologies themselves by excluding effects of population density in the areas covered by the exhaust plume. There are huge differences in the external costs of the different case studies ranging from below 1 to above $150 \mathrm{mEURO} / \mathrm{kWh}$. In all cases, but the biogas versus natural gas fuel cycle, we find a benefit for the biofuel application. The most favorable options are the use of forestry residues directly or via gasification in Sweden (s1-o, s2-o). The low external cost figures of the Swedish case studies at their original sites are partly due to the low population density there. For a number of cases, external costs are of the same magnitude as internal costs. This is especially true for all diesel engines and for coal-fired power plants placed in the UK or Germany. Of the biomass fuel cycles, only the rape-seed oil engine and the two Portuguese facilities exhibit external cost estimates in the same order of magnitude as the internal costs. Finally, it should be noted, that the Portuguese case (p2) is the only facility which would be made economic by internalizing the external costs calculated.

Fig. 5 indicates the specific $\mathrm{CO}_{2}$ abatement costs of the different case studies. Specific abatement costs are defined as the ratio of the specific cost difference over the difference of specific emissions of $\mathrm{CO}_{2}$-equivalents. When based on internal costs only, the cost difference is implicitly attributed to $\mathrm{CO}_{2}$ reduction exclusively. Therefore, we also indicate the $\mathrm{CO}_{2}$ abatement costs that arise, when external costs of conventional air pollutants at the original site and at Lauffen are added to the internal costs. For case studies where biomass has an advantage over the reference case with respect to conventional pollutants, $\mathrm{CO}_{2}$ abatement costs decrease. Although the BioCosts team views $\mathrm{CO}_{2}$ damage cost estimates as too uncertain to be directly included in the external cost estimates, we compare the $\mathrm{CO}_{2}$ abatement costs of the different case studies to damage cost estimates from literature. One of the lowest estimates found is the one by Nordhaus using his

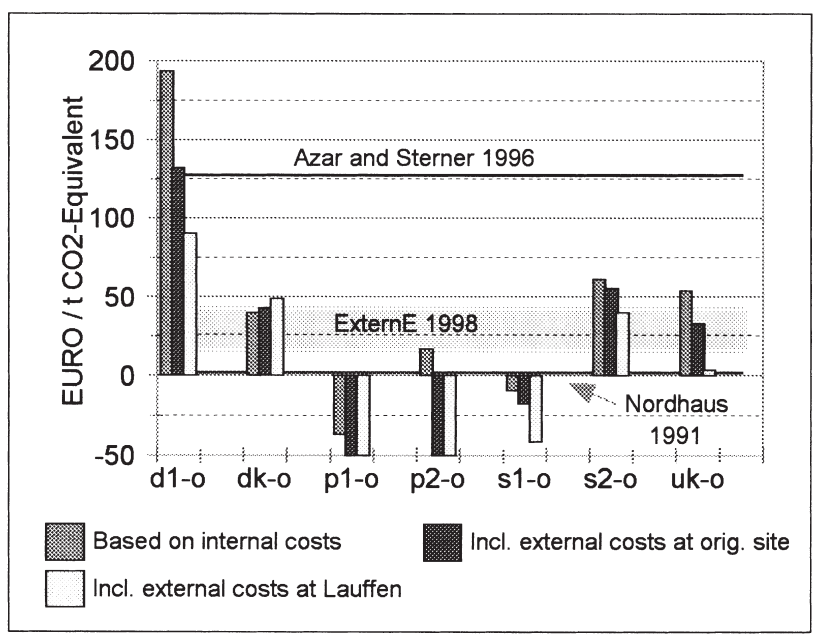

Fig. 5. Abatement costs of $\mathrm{CO}_{2}$-equivalents for the BioCosts case studies with and without considering external costs from damage to human health by conventional air pollutants, compared to damage cost estimates for global warming given by Refs 5, 17 and 18. The Nordhaus line is a $1.8 \mathrm{EURO} / \mathrm{CO}_{2}$. 
DICE model [17]. He obtains a figure of $1.8 \mathrm{EURO} / \mathrm{t} \mathrm{CO}_{2}$ (7.3 US\$/t C). As Azar and Sterner [18] point out, this low value is mainly due to using a rather high discount rate of $3 \%$ even for long-term damage, no equity weighting and a low retention time of $\mathrm{CO}_{2}$ in the atmosphere. With the same model, but with different assumptions on the three issues listed, Azar and Sterner reach values up to $127 \mathrm{EURO} / \mathrm{t} \mathrm{CO}_{2}$. In the ExternE project, calculations with the FUND model yielded a range of 15-42 EURO/t $\mathrm{CO}_{2}[5,19]$.

For the BioCosts case studies, three categories of fuel cycles can be distinguished. First, there are case studies which have negative $\mathrm{CO}_{2}$ abatement costs since they turned out cheaper than their reference cases (p1-o, s1-o). Hence, for them we have a classical win-win situation under prevailing economic conditions. Second, we have a case study with very high abatement costs, namely the rape-seed oil case (d1-o). Provided that the financial resources for mitigating global warming will be limited, this technology should definitely not be a first choice option. Third, we have the remaining case studies (dk-o, p2-o, s2-o and uk-o) which have medium range abatement costs that are more or less within the ExternE damage cost range. These are the most interesting candidates for future R\&D support and market penetration programs. Also, it has to be emphasized that three of the four cases (p2-o, s2-o, uk-o) would provide two benefits at the same time, mitigation of global warming and a reduction of human health impacts from conventional pollutants. Only in the case of biogas versus natural gas in Denmark (dk-o), mitigating global warming has to be paid for with a limited increase of impacts from conventional pollutants-with present technology.

\section{Conclusions and recommendations}

Even against the background of the many uncertainties involved in the quantitative results of the BioCosts project, there are a number of conclusions which are supported by several indicators and are more or less independent of the methodology chosen.

First of all and beyond doubt, biofuels are an important option to reduce net emissions of $\mathrm{CO}_{2}$ and, thus, to mitigate global warming, even though their respective contributions are of different magnitude.

For conventional pollutants, such as $\mathrm{NO}_{\mathrm{x}}, \mathrm{SO}_{2}, \mathrm{CO}, \mathrm{VOC}$ and particulate emissions, the picture is more differentiated. While there is generally an advantage of biomass with respect to $\mathrm{SO}_{2}$ emissions (except when compared to natural gas), there are cases where some of the other emissions are higher for the biomass fuel cycle than for fossil fuels. However, in well managed cases, the difference is either small or emissions occur at low levels anyway. Concerning external costs from human health impacts, there is an advantage of biomass when compared to coal and oil, and a (small) disadvantage compared to natural gas.

The strong implicit focus of ExternE on human health impacts, which is due to the exposureresponse functions and monetary values in the EcoSense model, suggests that the reduction of $\mathrm{NO}_{\mathrm{x}}$ needs to become a major policy target. This does not only hold for biomass, but also for fossil fuels since $\mathrm{NO}_{\mathrm{x}}$ emissions depend on the conversion technology in the first place. However, a number of technological options for reducing $\mathrm{NO}_{\mathrm{x}}$ emissions are available at moderate costs. Therefore, when introducing new technologies, low $\mathrm{NO}_{\mathrm{x}}$ emissions should be an important criterion. 
The combined production of heat and power has substantial advantages over separate production of these commodities if demand and supply can be brought into phase. With respect to the use of biomass, this is not only an issue of rational use of energy, but also of making optimal use of the land resources available for energy purposes. However, gas turbines and combinations of boilers and steam turbines are clearly preferable compared to internal combustion engines, as the latter have considerable problems with emissions of $\mathrm{NO}_{\mathrm{x}}$ and methane. However, it should be noted that in the near future combustion engines rather than turbines may be the only economically viable option if one wants to realize cogeneration potentials in areas with low demand densities. Thus, there is a trade-off between energy efficiency and mitigation of global warming on the one hand and health impacts of conventional pollutants on the other hand.

Furthermore, residues seem preferable to any energy crop, and perennial woody crops seem preferable to annual crops. This is due to the additional efforts associated with growing perennial and annual crops and to the complexity of the fuel preparation processes involved in converting biomass into convenient biofuels.

There are several other, mostly qualitatively assessed benefits and burdens that accompany the energy use of biomass. First, the use of forestry residues may contribute to reducing acidification levels in the forest as nitrogen is removed. Especially in Sweden, this is regarded as valuable and expresses itself in a high 'willingness-to-pay' demonstrated by the wide acceptance of the corresponding environmental taxes. Second, the use of biomass residues may facilitate waste disposal and reduce ground water pollution as illustrated by the production of biogas from animal slurry in the Danish case study and the application of sewage sludge for fertilizing short-rotation coppice in the UK case study.

Concerning impacts on biodiversity, water and soil quality, we have found negligible marginal effects in our case studies. This may change, however, if biomass fuel cycles are implemented at a larger scale. Adverse consequences may then be avoided if possible negative impacts are mitigated right from the beginning. For instance, energy crops should not be planted in areas which are or should be nature reserves, but in re-designated agricultural areas. Furthermore, the use of fertilizers has to be adapted to the actual uptake of the plants, and pesticides have to be applied sparsely. It may be worthwhile to examine in how far informative guidelines (which have been published in Europe and North America) and a tax on fertilizers, pesticides etc. could promote such a behavior.

Possible future competition for resources and land should receive careful consideration in planning for a sustainable development at an early stage. Thus, developments such as the increasing share of organic farming in Denmark may erode the potential of biomass. Changing the diet towards less meat consumption, on the other hand, may significantly increase the area available for energy crops, but requires major (and so far not very likely) cultural changes in our societies.

From the evaluation of local frameworks, it may be concluded that it is important to involve local stakeholders at an early stage. This can ensure an appropriate definition of and compliance with good practice guidelines and preserve rural amenity, thus helping to avoid local resistance to the new technologies.

The different case studies revealed a broad range of energy production costs. Two case studies were found to be economic at present fuel prices, mainly because the feedstock is available at low cost. Other case studies are up to $100 \%$ more expensive than their reference cases. Bringing down the internal costs of the promising biomass fuel cycles should be an important objective of $\mathrm{R} \& \mathrm{D}$ and market introduction strategies. 
For a number of the biomass technologies, including biogas and gasification of forestry residues and short-rotation coppice, we see a clear (economic) incentive to pursue their application. This is even more the case if one adopts the notion of strong sustainability as a policy guideline. In this case, the higher costs of biofuels and other renewable energy sources may be regarded as payments for an insurance against damage to the environment in general and the risk of global climate change in particular.

Nevertheless, market-based incentives should be used to support the market introduction of biomass-to-energy applications in order to select the most favorable application. Such mechanisms could be fuel taxes, emission taxes or tradable emission permits which may be justified as an internalization of external costs. However, reflecting the large uncertainties intrinsic in the external cost concept, the levels of such taxes should be determined by the objectives pursued rather than relying mainly on the external costs calculated. This principle is called the standard-price approach in economics and is well in line with the concept of strong sustainability.

Not surprisingly, calculating external costs with the EcoSense model revealed a crucial dependency on the site chosen and, consequently, the population density in the area covered by the exhaust plume. Thus, this methodology may be helpful when siting energy conversion facilities, even if its usefulness for a general assessment of technologies is limited.

The energy use of biomass may contribute moderately to additional employment. However, improvements in efficiency necessary for economic reasons are likely to reduce the labor input into biomass fuel cycles. Thus, the energy use of biomass cannot play a substantial role in solving the unemployment problem. There may be local benefits in rural areas especially retaining jobs which otherwise would be lost as a result of changing agricultural policies.

All in all, we emphasize that carefully chosen and well managed biomass fuel cycles can provide an important, if not indispensable, contribution to a sustainable future energy system for the European Union.

\section{Acknowledgements}

The BioCosts Project was funded in part by the European Commission in the framework of the Non Nuclear Energy Programme JOULE III, contract no. JOR3-CT95-0006. We would like to dedicate this paper to David O. Hall who was one of the initiators of the BioCosts project and who died only a few months after its completion.

\section{References}

[1] LTI-Research Group. Long-term integration of renewable energy sources into the European Energy System. Heidelberg: Physica, 1998.

[2] The BioCosts Research Group. Total costs and benefits of biomass in selected regions of the European Union (BioCosts). Final Report to the European Commission (JOR3-CT95-0006). Mannheim: Zentrum für Europäischer Wirtschaftsforschung (ZEW), 1998.

[3] Hohmeyer O, Walz R. The analysis of indirect emissions due to imtermediate production. In: Proceedings on an Expert Workshop on Life-Cycle Analysis-Methods and Experiences (Paris, May 21-22). Paris: OECD, 1992:228-37. 
[4] Vögels S. Technischer Fortschritt und seine ökonomischen und ökologischen Folgen: Das Beispiel der Elektriziätswirtschaft von Baden-Württemberg. Unpublished draft dissertation, University of Oldenburg.

[5] Commission of the European Communities DG XII editor. Final reports pf ExternE Phase III, vols. 1-6, forthcoming (preliminary version available at http://ExternE.jrc.es).

[6] Commission of the European Communities, DG XII editor. ExternE: externalities of energy. vols. 1-6. Luxembourg: Office for Official Publications of the European Communities, 1995.

[7] Friedrich R, Krewitt W, editors. Umwelt- und Gesundheitsschäden durch die Stromerzeugung. Externe Kosten von Stromerzeugungssystemen. Berlin: Springer, 1997.

[8] Hohmeyer O, Ottinger RL, Rennings K, editors. Social costs and sustainability. Valuation and implementation in the energy and transport sector. Berlin: Springer, 1996.

[9] Oak Ridge National Laboratory and Resources for the Future Inc. External costs and benefits of fuel cycles. A study by the US-DOE and the Commission of the European Communities. Reports 1-8. Washington DC: McGraw Hill/Utility Data Institute, 1994.

[10] RCC/Hagler, BAilly Inc. and Tellus Institute. New York State environmental externalities cost study. Final reports EP 91-50. Prepared for the Empire State Electric Energy Research Corporation. Reports 1-4. Albany, New York, 1993-95.

[11] Intergovernmental Panel on Climate Change (IPCC). Climate Change 1995. Economic and social dimensions of climate change. Contribution of Working Group III to the Second Assessment Report of the IPCC. Cambridge: Cambridge University Press, 1996.

[12] Miser HJ, Quade ES, editors. Handbook of systems analysis. New York: North Holland, 1985.

[13] Daly H. Beyond growth. The economics of sustainable development. Boston: Beacon Press, 1996.

[14] Patyk A, Reinhardt GA. Düngemittel—Energie und Stoffstrombilanzen. Braunschweig Wiesbaden: Vieweg Verlag, 1997.

[15] Groscurth H-M. Fallstudie Biomasse. In: Beschäftigungswirkungen des Übergangs von additiver zu integrierter Umwelttechnik. Final report to the 'Bundesministerium für Bildung, Wissenschaft, Forschung und Technologie (BMBF)'. Mannheim: ZEW, 1998.

[16] Pope III CA et al. Am J Resp Crit Care Med 1995;151:669-74.

[17] Nordhaus WD. Econ J 1991;101:920-37.

[18] Azar C, Sterner T. Ecol Econ 1996;19:169-84.

[19] Eyre N, Downing T, Hoekstra R, Rennings K, Tol RSJ. ExternE—global warming damages. Final Report of the Global Warming Sub-Task of the Project JOS3-CT95-0002. Brussels, 1997. 